\section{La imagen como brecha del tiempo}

Alejandra Niedermaier *

Resumen: El presente artículo desplegará algunas consideraciones sobre la configuración temporal de la imagen, su actuación sobre el imaginario individual y colectivo en virtud de que en la imagen habita una espesura de pensamiento y la posibilidad de apelar a la sensibilidad.

Palabras clave: Imagen - anacronía - imaginario - visibilización

[Resúmenes en inglés y portugués en la página 117]

${ }^{(*)}$ Fotógrafa, docente e investigadora. Magister en Lenguajes Artísticos Combinados (UNA). Profesora de la Universidad de Palermo en el Área de Investigación y Producción de la Facultad de Diseño y Comunicación desde el año 2008.

Coordinadora Académica de la Escuela de Fotografía Motivarte y docente del Posgrado de Lenguajes Artísticos Combinados de la UNA. Publica libros y ensayos acerca de los derroteros del lenguaje visual desde sus aspectos históricos y contemporáneos como así también sobre los aspectos didácticos. Forma parte del Cuerpo Académico de la Maestría en Gestión del Diseño. Miembro del Consejo Asesor Académico. Dirige el Proyecto de Investigación Giros y perspectivas visuales.

El presente artículo establece (nuevamente) continuidad con los formulados anteriormente. Especialmente con "La distribución de lo sensible y lo inteligible" (Cuaderno no 43), "Cuando me asalta el miedo (Cuaderno no 56) y "Posibilidades de la imagen en tiempos de oscuridad" (Cuaderno no 79 ).

Me referiré entonces a la imagen en términos culturales amplios, es decir, la imagen en su totalidad, independientemente del dispositivo que la origina.

Para desarrollar más las elucubraciones desplegadas en los mencionados textos, se partirá especialmente en esta ocasión, de su reconfiguración temporal, de su expresión anacrónica a efectos de dilucidar su actuación sobre el imaginario individual y colectivo y sobre lo sensible y lo inteligible, en virtud de que en la imagen habita tanto una espesura de pensamiento como una inteligibilidad en la sensación. Por otra parte, la reflexión resulta absolutamente pertinente en tiempos de cierto exceso y desmesura visual. 


\section{Su actuación sobre el imaginario. Derroteros}

Bajo este apartado se continuará realizando una especie de arqueología de la distribución de lo sensible y lo inteligible en el ámbito de las prácticas relacionadas con la imagen a efectos de poder detectar tanto las continuidades como las discontinuidades y sus espacios intersticiales.

En el transcurso del tiempo la imagen enarbola su incidencia sobre lo simbólico y sobre el imaginario. En este sentido su accionar sobre el pasado y sobre el presente adquiere varias y mutantes significaciones. La sobredeterminación de la cual habla Georges Didi Huberman se relaciona con su capacidad de convertirse en el reflejo del "inconsciente de la representación" (2006, pp. 22-44) y transformarse de este modo en un síntoma. Por ello se puede inferir que la imagen conlleva "duraciones heterogéneas" (p. 45).

En muchas ocasiones la imagen es observada en un presente, en un ahora. La misma se refiere a un tiempo pasado y sus huellas (representativas, simbólicas, imaginarias) serán guardadas para un futuro ${ }^{1}$. En tal sentido, se produce una dislocación entre el tiempo de la experiencia vivida y registrada por la imagen (foto, cine, video) y el tiempo en que se aprecia esa imagen a través de sucesivas miradas. Incluso, en este interjuego temporal, se producen traslados entre las esferas privadas y públicas: imágenes que refieren a vivencias privadas se pueden convertir -desde el análisis de la historia- en un modo hermenéutico y colectivo de estudio. Cuando se realiza un análisis histórico de retratos realizados en diversas ciudades, y a pesar de que su contenido aparente nos parezca similar, no debemos olvidar que para cada ciudad significa una forma de autoreconocimiento y pertenencia. La vida de un pueblo o de una ciudad, además de sus atributos urbanos y geográficos, es la suma de las relaciones personales y del entramado social que lo vincula con el mundo. La sumatoria de cada uno de los retratos otorga entonces un retrato comunal.

Así, si se adhiere a la idea de Foucault de que el saber sirve "para cortar" (en GDH p. 27), tal vez la figura a considerar sea la de un corte temporal transversal que otorga una especial atención a los pliegues que ese mismo corte genera. Considerar en definitiva el relámpago que produce la imagen sobre el imaginario y lo simbólico como reflejo de lo subyacente, lo latente.

El término inervación utilizado por Walter Benjamin en varios de sus textos proviene del ámbito médico-fisiológico y fue utilizado por Sigmund Freud para designar el traslado de cierta energía a alguna parte del cuerpo produciendo fenómenos sensitivos. Es a partir de este concepto de inervación que se considera la intervención de la imagen sobre lo simbólico y sobre el imaginario. La inervación propicia pues la asociación de una recepción mimética del entorno y acomete con la percepción y la visión en momentos determinados. Por eso favorece la capacidad para la imaginación y también para la acción en tanto deviene en gesto poietico e impulsa una praxis vital.

A su vez, Benjamin hace referencia a la capacidad de la imagen de establecer analogías y descubrir formas. En su ensayo "Noticias sobre plantas" menciona que Karl Blossfeldt otorga "la importante amplificación que les da para que esas formas se deshagan del velo que nuestra pereza arrojó sobre ellas”. (en GDH p.182) Se podría preguntar entonces si la imagen no funcionaría como un punctum o un aura que propone levantar los ojos a través de una mirada heurística, hermenéutica y situada. 
Así tras el impacto inicial, las imágenes tomadas por Lee Miller, Margaret Bourke White, Éric Schwab, Germaine Krull y George Rodger en distintos campos de concentración, acercaron, en el transcurso de su legibilidad histórica, unas posibilidades de reflexión acerca de los terribles hechos ocurridos. Se puede distinguir asimismo la condición de posibilidad de la imagen de producir modificaciones sobre el devenir de la humanidad a través de la instantánea que circulara en 2017 (varias veces reproducida en diversos formatos) del niño sirio ahogado en las costas de Turquía dando cuenta de la problemática contemporánea de los refugiados.

Esta misma condición de posibilidad es propuesta por el artista visual francés Emeric Lhuisset $^{2}$ en la instalación fotográfica realizada en el 2008 que evidencia que el relámpago, el punto crítico se da muchas veces cuando se puede mostrar las diferentes contradicciones y se convierte en un elemento objetivador del escenario circundante. Por un lado, objetivador pero también, adjetivador: las imágenes pueden tratar de mostrar (según distintos puntos de vista), convencer, seducir o representar hiperrealidades. Justamente por eso, proceden en ocasiones por intromisión y resultan instituidoras.

La imagen atraviesa pues el horizonte temporal y cultural de un momento determinado ya que posibilita la percepción de las relaciones y las correspondencias entre las cosas al volver a situar y volver a contextualizar.

Uno de los aspectos más interesantes de la imagen (y es lo que sugieren continuas apreciaciones) es la imposibilidad de detener el debate en torno a ella.

\section{Su actuación sobre el tiempo}

"Cada época sueña a la siguiente." Jules Michelet (en Benjamin, 2005, p. 1012)

Benjamin reconocía que en la imagen dialéctica se halla la noción de tiempo y que ésta ya estuvo prefigurada en Hegel. Sin embargo, su concepción de la imagen dialéctica trabaja especialmente sobre el intersticio temporal (que incluso extiende a la moda).

El momento temporal está mediado pues por lo inteligible y lo sensible de cada tiempo. Benjamin explica que la diferencial de tiempo surge del encuentro de temporalidades diversas enlazando, de algún modo, con una parte de la clásica definición de aura: “(...) la aparición irrepetible de una lejanía por cercana que ésta pueda hallarse.” (p. 194) Además, porque la imagen "(...) relampaguea de una vez para siempre en el instante de su cognoscibilidad (...)" (p. 67) y porque "(...) es aquello en lo cual lo que ha sido se une como en un relámpago con el ahora en una constelación. En otras palabras: la imagen es la dialéctica en suspenso." (p. 100). De este modo explicita la interrupción de un continuum.

Por su parte, Henri Bergson ya establecía en 1930: "Que podamos insertar lo real en el pasado y trabajar así hacia atrás en el tiempo, nunca lo he pretendido. Pero que podamos acoplar ahí lo posible, o más bien que lo posible mismo vaya a acoplarse ahí en todo momento, eso no podemos dudarlo." 
Al respecto, el psicoanalista René Kaës (1996) identifica: “(...) nada de lo que haya sido retenido podrá permanecer completamente inaccesible a la generación que sigue, o a la ulterior. Habrá huellas, al menos en síntomas que continuarán ligando a las generaciones entre sí (...)" Comprender estas características resulta de singular importancia cuando se realizan exploraciones sobre imágenes pasadas en virtud de que éstas son continente y contenido de la memoria ya que cada imagen lleva en sí la medida de su tiempo. En algunos casos, la imagen es conformadora de la memoria, en otros, la memoria está repleta de ella. Las categorías de espacio y de tiempo, atributos inherentes al lenguaje visual, conforman, tal como lo expresara Immanuel Kant, la estructura en el pensamiento humano que permite relacionarse con el mundo. Podemos pensar entonces que cada época, cada sociedad posee temporalidades diferentes porque su espacio no es completado por situaciones que se desarrollan para siempre, sino por procesos, por acontecimientos. Jacques Derrida en Dar el tiempo manifiesta que el tiempo es invisible y que se sustrae a la visibilidad. Sin embargo, en el lenguaje visual el tiempo aporta justamente las variables cronotópicas a las que se refería Kant. Tanto en la imagen fija como en la de movimiento, el tiempo se percibe como una manifestación de la duración de la naturaleza del tiempo (la durée mencionada por Bergson). Volviendo a Derrida, se coincide con que la palabra tiempo designa menos el tiempo mismo que las cosas con las que se llena ese tiempo. En este caso, son tiempos sucesivos o superpuestos: el tiempo de la toma de la imagen, el tiempo de su edición y, finalmente, el tiempo de su visualización.

Si se indaga en la naturaleza del tiempo, se puede encontrar que la duración significa creación de formas, posibilidad de invención, elaboración continua de lo nuevo. La duración no es solamente la experiencia vivida, es su condición de posibilidad y de ampliación. Por eso se puede considerar a la imagen como un síntoma que se abre al tiempo. Su visualización despliega la duración.

Bergson interrogaba: "el tiempo es lo que impide que todo se dé de golpe. Retrasa, o más bien es retraso. Por tanto, debe ser elaboración. ¿No sería entonces vehículo de creación y de elección?” En Memoria y vida añadía: “Cuanto más profundicemos en la naturaleza del tiempo, tanto más comprenderemos que duración significa invención, creación de formas, elaboración continua de lo absolutamente nuevo." (p.13)

El gesto creador y el gesto de la elección del encuadre, propios del lenguaje visual responden esta pregunta. El filósofo continuó pensando sobre el tema: "Artesanos de nuestra vida, incluso artistas (...) trabajamos continuamente en modelar, con la materia que se nos facilita por el pasado y el presente, por la herencia y las circunstancias." De este modo hace referencia al carácter anacrónico de la creación en virtud de que la duración tampoco es homogénea. El proceso de creación es un acontecimiento que abreva en los indicios que el tiempo origina a través distintos momentos, épocas y generaciones.

En la modalidad contemporánea del Fotolibro/Libro de artista hallamos una temporalidad a través de la secuenciación. Cada imagen contiene su propio espacio y tiempo potencial que junto con otras configuran una temporalidad narrativa. La duración aparece así a través del ordenamiento sintáctico. Hallamos también una especie de tiempo elíptico que se manifiesta a través de saltos, aceleraciones y retrocesos. 


\section{¿Oculta o visibiliza?}

El concepto de Jacques Lacan de que la visión no es la mirada y las consideraciones de Donald Winnicott sobre el rol de la mirada de la madre en tanto devolución de la propia imagen del niño son aplicables a las elucubraciones sobre el alcance de lo que la imagen visibiliza.

La mirada de la madre le devuelve a la criatura una idea de su propia imagen lo que induce al siguiente pensamiento: "cuando miro se me ve, y por lo tanto existo" (p. 183).

Ya en el texto "Cuando me asalta el miedo, creo una imagen", en el Cuaderno no 56, se mencionaba que los psicoanalistas (Melanie Klein y Jacques Lacan entre otros) encontraron que durante el estadío del espejo, al captar el niño su imagen sobre una superficie espejada puede configurar su propio esquema corporal. Este hallazgo resulta fundamental para su desarrollo psíquico, la formación de su personalidad y es fundadora de posibles identificaciones. Las identificaciones se fundamentan en un lugar simbólico, el Ideal de Yo. Las imágenes ocupan un lugar dentro del Ideal del Yo en tanto propulsoras de ideales sociales y éticos.

El pensamiento de Winnicott amplía esta observación otorgándole particular importancia a la mirada del Otro (en su caso, la madre) en tanto constitución de la existencia y condición de posibilidad de relacionarse. En el caso de la imagen, la mirada atenta (no la visión) confiere su condición de existencia y la condición de posibilidad de procurar una significación. Es, a partir de esa significación, que se puede emprender el análisis paradigmático y sintagmático de la visibilización o del ocultamiento. Incluso, volviendo a Winnicott, podemos relacionar el tiempo de la visibilización y el tiempo del ocultamiento de una imagen con las posibilidades de elaboración de una experiencia. Las imágenes resultan así objetos transicionales entre lo público y lo privado, entre lo interno y lo externo e inciden sobre el imaginario. En este mismo sentido, Cornelius Castoriadis consideraba que el tiempo imaginario resulta simultáneamente significativo y dador de significación. (2014, p. 234) Se puede comenzar a examinar la determinación de la mirada del productor para luego explorar otros aspectos. Lacan asociaba entonces:

En lo visible, la mirada que está afuera me determina intrínsecamente. Por la mirada entro en la luz, y de la mirada recibo su efecto. De ello resulta que la mirada es el instrumento por el cual se encarna la luz y por el cual -si me permiten utilizar la palabra, como lo suelo hacer, descomponiéndola -soy fotografiado. (1964, p.113)

Hay una larga tradición sobre ciertas posibilidades de visibilización de la imagen en el ámbito de la psiquiatría. Conocidos fueron los usos, en su tiempo, como modo de representación objetivo y científico, para detectar casos. Fotografías tomadas por el Dr. Duchénne de Boulogne y Paul Regnard entre otros, fueron publicadas en libros como Iconographie photographique de la Salpetriere en 1880. En Inglaterra, el Dr. Hugh Welch Diamond, miembro fundador de la Royal Photographic Society y director del departamento de mujeres del manicomio del condado de Surrey, mencionaba "la peculiar aplicación de la fotografía al esclarecimiento de la locura". Y agregaba: 
El fotógrafo atrapa en un instante la nube permanente, la tormenta pasajera o el sol del alma y de este modo permite al metafísico observar y establecer la conexión entre lo visible y lo invisible (...) (en Tagg, 2005, p. 104)

La contracara de la presunción de visibilización estaba en las fotos solicitadas por Thomas John Barnardo para el Home for destitute lads (Residencia para chicos indigentes) ya que utilizaba las imágenes como argumento para recibir fondos. La acusación informó que no los mostraba en su estado real sino que rasgaba sus ropas, entre otros recursos para aumentar la sensación de desolación. En ambos casos se establecía una mirada biopolítica y panóptica.

Se puede inferir pues que los textos visuales juegan con el sentido de su materia, sentido como sensualidad (en términos de su palpable vivacidad y seducción) y sentido como significación. A partir de esa sensualidad y desde ideales sociales, estéticos, políticos y éticos, la imagen puede visibilizar, ocultar y, además, manipular y disciplinar al modelar deseos y afectos.

También desde la historia de la fotografía, es dable analizar la controversia suscitada con la famosa exposición The family of $\mathrm{man}^{3}$. Roland Barthes y Allan Sekula, entre otros y en fechas diferentes, criticaron la muestra como un esfuerzo esteticista para mostrar la "condición humana" en medio de la Guerra Fría. En su voluntad por exacerbar una sensación de tranquilidad en sus espectadores, lograba provocar una desmovilización generalizada. De este modo propiciaba en el receptor un pasaje de un sujeto político a un sujeto consumidor. A propósito, la Urban League le dio a Edward Steichen (su curador) un premio "por hacer que la humanidad esté orgullosa de su humanidad." (en Stimson, 2009, p. 103) Sobre la posibilidades de visibilización de la imagen fotográfica se encuentra otro antecedentes histórico: Alexander Rodchenko declaraba que todo hombre moderno debe fotografiar y ser fotografiado ya que encontraba en ese medio las posibilidades de una directa representación. Sin embargo, con el correr del tiempo y en torno al disciplinamiento en el hábito de la selfie, además de sus características lúdicas, se puede encontrar una tensión entre lo representacional imaginario y lo corpóreo-material propiamente dicho. En este y en otros casos nos encontramos frente a un síntoma del propio narcisismo, del deseo de las personas de estar dentro de la imagen y de "producirse" para la misma para, de algún modo, transformarse en su propio objeto publicitario. Tal vez podamos hablar de un nuevo modo de acercamiento, ya no hay una búsqueda de conocer al otro sino de conocerlo a través de la propia imagen. Así, en muchos casos la imagen resulta prisionera de este accionar pero también del accionar de los mecanismos de poder que también la construyen a través de sí. Para Benjamin, la relación cuerpo/imagen emite el destello de un Jetztzeit, es decir de un tiempo actual. Este tipo de "visibilizaciones" son propiciadas además por las redes, en especial por la que obliga a ver una imagen dentro de las 24 hs. porque después la misma desaparece, creando así una dependencia y una mezcla de ficción y realidad.

Dentro de este análisis sobre la visibilización es necesario incluir el carácter ontológico y retórico de la transparencia de la fotografía. Incluso en las escenificaciones de las que hoy es objeto. Se aprecia por tanto un énfasis en la construcción, fabricación, forzado y escenificación de la imagen. Siempre apoyándose en una supuesta transparencia se puede 
entrever, en ocasiones, el objetivo de provocar un consenso a través de la manipulación de mostrar lo horroroso, lo íntimo y lo siniestro.

Además, en cuanto a la visibilización y el ocultamiento, hallamos una permanente oscilación entre presencia y ausencia. La pulsión escópica solicita el vislumbramiento pero las posibilidades de manipulación tanto históricas como contemporáneas se encargaron y encargan también del ocultamiento total o parcial de algunos sucesos. Un ejemplo de ello fue durante la celebración del Centenario en la Argentina en 1910. Las fotografías publicadas en los álbumes especialmente creados para la ocasión y también en algunos medios desplegaron un imaginario que favorecía la ilusión de una gran y mancomunada nación al estimular el contacto, lo vincular y lo fático. Precisamente, estas imágenes adscriben a lo que Michel Foucault mencionaba en su libro La Arqueología del Saber: “(...) mostrar según qué reglas una práctica discursiva puede formar grupos de objetos, conjuntos de enunciaciones, juegos de conceptos, series de elecciones teóricas" (en Niedermaier, 2012, p. 168). Pero un imaginario no da cuenta solamente de la esperanza sino también del debate, del debate que surgía en correspondencia con la presencia de grupos politéticos. Es decir, hubo un conjunto de fotografías que documentaron los momentos de honda tensión en los cuales se podían entrever los conflictos ligados, por un lado, a la lucha de clases (la protesta obrera, el anarquismo, el socialismo) y, por el otro, a las demandas y presiones de las clases medias por democratizar el régimen político y los canales de acceso a las instituciones culturales.

A su vez, dentro de esta exploración sobre la imagen como síntoma se debe considerar las imágenes ausentes. Ausentes por temas no abordados, ausentes que en algún momento existieron pero que ya no se hallan o no se miran. Ausentes por haber sido prohibidas, censuradas y tal vez destruidas. Se halla entonces un espacio intersticial entre lo que es dado a ver y lo que no. A propósito, Jacques Derrida sugería reclamar un "derecho de mirada" que los ciudadanos pudiesen solicitar a los medios de comunicación, es decir, a los mecanismos de manipulación (en Merlín, 2017, p. 19).

Cabe realizar aquí una distinción entre las dos esferas indicadas por François Soulages: arte y sin arte como instancias diferenciadas del gesto creador. Lo construido desde el sin arte dinamiza lo social, lo institucional y su discurso está absolutamente mucho más expuesto a posibilidades manipulatorias tanto desde sus condiciones de producción como de recepción. Como ya se indicara la imagen (en especial la fotográfica) mantiene cierto estatuto ontológico de veracidad aunque ella no refleje lo real/verdad. Una de las características actuales de los procesos neoliberales es el coqueteo con la transparencia sin que ésta realmente se produzca.

Por su parte, dentro del terreno del arte y, a partir de la teoría estética de Jacques Rancière, Georges Didi Huberman, Nelly Richard y Ticio Escobar, entre otros, se puede hablar de una vitalidad entre ésta, la emergencia de lo político y la transformación de orden social. $\mathrm{El}$ arte tiende a propiciar nuevas posibilidades discursivas.

La nueva condición de posibilidad de visibilización tiene, entonces, relación con la subjetivación política que redefine lo que es visible, decible y abre el espectro de quienes pueden hacerlo. En tal sentido, Rancière considera que el arte "es político por la misma distancia que toma con respecto a sus funciones, por la clase de tiempos y de espacios que 
instituye, por la manera en que recorta este tiempo y puebla este espacio" (2011, p. 33). Así lo político del arte, tiene una estrecha relación con los procedimientos poiéticos que el gesto autoral elige para hacer visible y configurar una nueva distribución de lo sensible y lo inteligible. Este es el caso de los dos proyectos que se exponen a continuación. Uno está ligado al espacio exterior y el otro ocupa el intersticio entre lo exterior y lo interior. Por un lado el proyecto de Pablo Piovano denominado El costo humano de los agrotóxicos y por otro, el de los fotógrafos Belén Grosso y Sebastián Pani denominado Y un día, el fuego. El primero alude, como su nombre lo indica, a las consecuencias sobre la salud de la población ante el uso de agrotóxicos en distintas provincias de la Argentina. En el segundo, ambos dan cuenta del fenómeno femicida de quemar literalmente a la mujer cercana, conyugue en general.

En el prólogo del libro Photographie contemporaine Art contemporaine, Soulages habla de que el desafío del arte no tiene relación con fotografiar el hecho en sí mismo sino con su posibilidad de expandirlo, de desarrollarlo. (p. 13) En estos proyectos estamos frente a una imagen que escapa lo documental (sin eliminarla sin embargo) sino uniéndola casi indisolublemente a lo simbólico. En 1926 John Grierson definía lo documental como una exposición de los hechos, como una retórica de la inmediatez y la verdad. Si bien esto está presente en ambos proyectos por ser signos de existencia, lo que se encuentra además es que ya no se trata tan solo de mostrar lo Real sino también de enunciar lo que subyace ante cada fenómeno. Supone una capacidad de vincular la representación de las cosas con la subjetividad, con lo que esencialmente despiertan. Esto tiene relación con la actual traslación de los géneros fotográficos. Los presentes desplazamientos conforman una estética a la vez, que da cuenta de una densa urdimbre, del roce, de la espesura y de la complejidad que, con diferentes grados de presencia, se insinúa en cada imagen. La fotografía posee la posibilidad de abordar lo irrepresentable y lo inimaginable de situaciones de alta intensidad traumática social en donde aparece el límite, los márgenes de lo humano/inhumano. Se acuerda en este sentido con Giorgio Agamben cuando manifiesta que pensar significa percibir la exigencia que tiene lo real, hacer justicia no sólo con las cosas sino también con sus lágrimas (2017, p. 51) Por eso, y a través de una cierta omnitemporalidad, la imagen ha contribuido -y sigue contribuyendo- a una honda reflexión y a una posibilidad de elaboración.

Estos casos, como también los de los fotógrafos Ismail Ferdous y Taslima Akhter sobre el incendio ocurrido en 2013 en una precaria fábrica de indumentaria llamada Rana Plaza en Savar, un poblado suburbano de Dhaka, Bangladesh, reúnen también el aspecto cuantitativo de la fotografía documental/autoral que busca lograr alguna reacción.

Así, el desfase temporal con el suceso de los nombrados proyectos contribuye a su despegue del género documental clásico. Las imágenes aúnan, entonces, dos momentos: el de la experiencia del gesto creador con la abstracción de lo observado, del enunciador con el objeto enunciado y transforman una experiencia individual en una forma social.

De sus trabajos emerge el concepto, desarrollado líneas arriba y en "La imagen en tiempos de oscuridad”, de síntoma como expresión de un malestar. Las imágenes por su carácter de inscriptores de sentido, dan cuenta del síntoma y contribuyen a una mirada crítica y/o redentora de lo real, según sea el caso, pero siempre colaboran con su hermenéutica. Coadyuvan con la construcción de un espacio abierto y en permanente disputa. 
Los realizadores visuales que visibilizan situaciones que comprometen al ser humano en distintos aspectos desarrollan un activismo en distintos dispositivos y, junto a periodistas, escritores y otros, amplían el alcance de la denuncia y se inscriben en una muy contemporánea hibridación multimedia. Lucy Lippard identifica al Caballo de Troya como la primera obra de arte activista. En todos los proyectos activistas se detecta una experiencia que procede de la conexión del productor con algún hecho de la realidad que lo circunda. Por eso se pueden divisar las determinaciones psicológicas e ideológicas (en tanto compromiso) pero también las competencias lingüísticas (acerca de los dispositivos) y culturales. Tal como expresa Taslima en la entrevista que le hiciera la fotógrafa y docente inglesa Karen Knorr, "theory emerges through practice/la teoría emerge en la práctica". Y agrega: "I think without any ideological and theoretical viewpoint one can't make his/her work strong./ Creo que sin un punto de vista ideológico y teórico no se puede realizar un trabajo sólido." Por otra parte, existe una interrogación sobre si hay una cierta coherencia interna entre la propuesta (de los fotógrafos) y la recepción exterior. En el circuito comunicacional que atraviesa un mensaje estético se produce una transferencia de subjetivación entre el productor y el receptor. Por eso, el análisis de la imagen debe ser realizado, no sólo a partir de sus particularidades estéticas, sus condiciones de producción (las condiciones de posibilidad para su aparición están conformadas por la deliberación temática, la elección de los materiales, la puesta en acto de los presupuestos ideológicos, socio-políticos y culturales, es decir, todo lo que forma parte del gesto del productor) y su recepción. Así el espectador es convocado a una mirada que descubra mucho más allá de lo que se muestra, que perciba la irradiación que toda obra pretende convocar y distinga su deseo de inquietar.

\section{Conclusiones momentáneas}

La imagen a menudo tiene más de memoria y más de porvernir que el ser que la mira"

Georges Didi Huberman (2006, p. 12)

Volvemos finalmente a la posibilidad de la imagen en tiempos de oscuridad, conformada por remolinos de tiempo que potencian una pensatividad anacrónica, a partir de cierta incompletud del pasado y del presente, con el objeto de otorgarle sustancia al futuro.

Retomamos la necesidad de recuperar la libertad del gesto del productor ya que en muchos casos éste ha perdido autonomía en función de la autoridad del poder mediático convirtiendo a la imagen en un producto blindado (Soulages, 2018). El productor debe poder aunar libremente la dimensión estética junto a la dimensión ética y política.

Regresamos a la idea de movimiento, de recomienzo del gesto autoral, del gesto vivificador que señala lo disruptivo y que trabaja la imagen como "potencia que desata" (Rancière, 2011, p. 52) una mirada sensible en el receptor. 


\section{Notas}

1. Pensadores como Walter Benjamin, Georges Didi Huberman, John Berger y François Soulages, entre otros, sostienen que en la imagen anida también el devenir. Benjamin en su ensayo "La obra de arte en la época de su reproductibilidad técnica" cita la siguiente frase de André Breton: "La obra de arte sólo tiene valor cuando tiembla de reflejos del futuro" (2007, p. 175)

2. Se trata de la Declaración de los Derechos del Hombre enmarcada tradicionalmente con un fino marco negro por la cual se asoma una ametralladora en su reverso. (https:// www.emericlhuisset.com/dh.htm)

3. Exhibida por primera vez en 1955 en el Museo de Arte Moderno de New York y que itinerara posteriormente por 37 países. Se trataba de 503 fotografías tomadas por 273 fotógrafos de 68 países con la curaduría de Edward Steichen que, en ese momento era el director del Departamento de Fotografía de ese museo.

4. Traducción de la autora

\section{Listas de Referencias Bibliográficas}

Agamben, G., (2017), ¿Qué es la filosofía?, Buenos Aires, Adriana Hidalgo

Agamben, G. (2009), Signatura rerum, Buenos Aires, Adriana Hidalgo

Arfuch, L. y Devalle, V. (comp.), Visualidades sin fin, Buenos Aires, Prometeo

Benjamin,W. (2005), El libro de los pasajes, Madrid, Akal.

Benjamin, W. (1999), "El surrealismo. La última instantánea de la inteligencia europea”, en Imaginación y Sociedad, Madrid, Ed. Taurus.

Benjamin, W. (2007), "El arte en la época de la reproducción técnica", en Conceptos de filosofía de la historia, La Plata, Terramar Ediciones

Bergson, H. (1930), "Lo posible y lo real", Revista Nordisk Tidskrift

Bergson, H. (1977), Memoria y vida. Textos escogidos por Gilles Deleuze, Madrid, Alianza Editorial

Derrida, J. (1995), Dar el tiempo, Barcelona, Paidós

Didi Huberman, G. (2006), Ante el tiempo, Buenos Aires, Adriana Hidalgo

Didi Huberman, G.s (2015), Remontajes del tiempo padecido, Buenos Aires, FUC/Biblos

García, L. I., "Una política de las imágenes: Walter Benjamin, organizador del pesimismo" en Escritura e Imagen, Vol II, 2015, hallable en https://www.academia.edu/22801767/ Una_pol\%C3\%ADtica_de_las_im\%C3\%A1genes_Walter_Benjamin_organizador_del_ pesimismo

Holert, T. (2019), "Epistemic violence and the careful photograph" en ex-flux Journal \#96 Indij, G. (comp. 2014), Sobre el tiempo, Buenos Aires, La Marca Editora

Kaes, R.; Faimberg, H.; Enriquez, M.; Baranes J. (1996), Transmisión de la vida psíquica entre Generaciones, Buenos Aires, Ediciones Amorrortu

Lacan, J. (1997), El Seminario 11. Sobre los cuatro conceptos fundamentales del psicoanálisis, Buenos Aires, Paidós 
Lippard, L. "Caballos de Troya: arte activista y poder” en Marzo Jorge Luis (comp.2006), Fotografía y activismo, Barcelona, Gustavo Gili

Merlín, N. (2017), Colonización de la subjetividad, Buenos Aires, Letra Viva

Niedermaier, A. (2012), "El privilegio de la fotografía" en AA.VV., Imágenes de la Nación, Buenos Aires, Teseo

Rancière, J. (2011), El destino de las imágenes, Buenos Aires, Prometeo

Rancière, J. (2011), El malestar en la estética, Buenos Aires, Capital Intelectual

Stimson, B. (2009), El eje del mundo. Fotografía y nación, Barcelona, Gustavo Gili

Soulages, F.; Marc, T. (comp. 2012), Photographie contemporaine \& Art contemporain, Paris, Klincksieck

Tagg, J. (2005), El peso de la representación, Barcelona, Gustavo Gili

Winnicott, D. (2012), Realidad y juego. Buenos Aires, Gedisa

\section{Sitios web:}

Entrevista de Karen Knorr a Taslima Akther (2012) en https://globalarchivephotography. com/project/the-life-struggle-of-garment-workers/\#project-interview

Abstract: This article will display some considerations on the image temporary settings; its influence on the individual and collective imaginary due that pictures inhabit a thickness on thoughts and have the possibility to appeal the sensibility.

Keywords: Image - anachronism - imaginary - visibilization

Resumo: Este artigo irá mostrar algumas considerações sobre as configurações de imagem temporárias, seu desempenho sobre o imaginário individual e coletivo em que imaginei habita um matagal de pensamento e a possibilidade de apelar para a sensibilidade.

Palavras chave: Configurações temporárias - imaginário - pensamento - sensibilidade

[Las traducciones de los abstracts fueron supervisadas por el autor de cada artículo] 